\title{
Mechanisms of Hepatic Cholestatic Drug Injury
}

\author{
Tea Omanović Kolarić ${ }^{1,2}$, Vjera Ninčević ${ }^{1,2}$, Robert Smolić ${ }^{1}$, Martina Smolić*1,2 \\ and George $\mathrm{Y} \mathrm{Wu}^{3}$ \\ ${ }^{1}$ Department of Pharmacology, Faculty of Medicine Osijek, Osijek, Croatia; ${ }^{2}$ Department of Pharmacology, Faculty of Dental \\ Medicine and Health, Osijek, Croatia; ${ }^{3}$ Department of Medicine, Division of Gastroenterology-Hepatology, University of \\ Connecticut Health Center, Farmington, CT, USA
}

\begin{abstract}
Drug-induced cholestasis represents a form of drug-induced liver disease that can lead to severe impairment of liver function. Numerous drugs have been shown to cause cholestasis and consequently bile duct toxicity. However, there is still lack of therapeutic tools that can prevent progression to advanced stages of liver injury. This review focuses on the various pathological mechanisms by which drugs express their hepatotoxic effects, as well as consequences of increased bile acid and toxin accumulation in the hepatocytes. Citation of this article: Kolarić TO, Ninčević $V$, Smolić $R$, Smolić M, Wu GY. Mechanisms of hepatic cholestatic drug injury. J Clin Transl Hepatol 2019;7(1):86-92. doi: 10.14218/ JCTH.2018.00042.
\end{abstract}

\section{Introduction}

The liver is the central organ responsible for the selective uptake, metabolism and excretion of endogenous and exogenous compounds, including drugs. ${ }^{1,2}$ The anatomical location and the activity of uptake transporters that facilitate accumulation of drugs in hepatocytes make this organ susceptible to drug-induced liver injury (DILI). ${ }^{1}$ DILI is the leading cause of liver transplantation in Western countries due to its role in causing acute fulminant liver failure. It also represents the primary reason for the failure of pharmaceutical agents during drug development. ${ }^{2,3}$ However, it has been reported that only $10 \%$ of jaundiced patients (who already have symptoms of liver disease) with underlying hepatocellular injury will develop acute liver failure. ${ }^{4,5}$ This indicates that only a small fraction of the overall group experienced the above-mentioned failure.

Nevertheless, DILI represents a serious clinical problem due to its lack of standardized diagnostic criteria, delay in diagnosis, unpredictable nature, and potentially fatal course. ${ }^{6-8}$ The most severe clinical patterns of DILI are cholestatic and mixed cholestatic and hepatocellular liver injury. ${ }^{2}$ Regarding

Keywords: Drug-induced liver injury; Bile acids; Cholestasis.

Abbreviations: $A B C$, ATP-binding cassette; BA, bile acid; BSEP, bile salt export pump; CA, cholic acid; DILI, drug-induced liver injury; GCDCA, glycochenodeoxycholic acid; GSH, glutathione; MDR, multidrug resistance; MRP, multidrug resistance-associated protein; NTCP, sodium-taurocholate cotransporting polypeptide; OATPs, organic anion transporting polypeptides.

Received: 5 July 2018; Revised: 18 December 2018; Accepted: 8 February 2019 *Correspondence to: Martina Smolic, Department of Pharmacology, Faculty of Medicine Osijek, J. Huttlera 4, Osijek 31000, Croatia. Tel: +38-531512800, E-mail: martina.smolic@mefos.h clinical patterns, an $\mathrm{R}$ value, which is defined as the ratio of serum alanine aminotransferase/upper limit of normal to serum alkaline phosphatase/upper limit of normal can be helpful in separating DILI into the following three patterns of liver injury: cholestatic injury, with $\mathrm{R}<2$; mixed injury, with $2<\mathrm{R}<5$; and, hepatocellular injury, with $\mathrm{R} \geq 5 .{ }^{4}$ Among these three patterns, cholestatic drug injury takes place in $20-40 \%$ of cases. ${ }^{9}$ Additionally, patients with cholestatic injury generally have better outcomes than those experiencing a hepatocellular injury.

Cholestasis can occur as a consequence of impaired formation of bile, or in the case of physical obstruction to the bile flow after it has been secreted from hepatocytes. Drug-induced cholestasis can be caused by inhibition of bile acid (BA) transport (direct or indirect, which includes regulation of transporter localization or expression), hypersensitivity reaction, and direct injury to bile ducts, as well as mitochondrial damage. ${ }^{1}$ The aim of this review was to evaluate and compare the major pathophysiological mechanisms involved in cholestatic liver injury induced by various drugs.

\section{Epidemiology}

The incidence of DILI in general populations was estimated to be between $1 / 100,000$ and $20 / 100,000$ in developed countries, ${ }^{10,11}$ and was estimated to be responsible for around $10 \%$ of acute hepatitis cases. ${ }^{12}$ Data from France suggested that the annual incidence of DILI was roughly $13.9 / 100,000$. In the USA, idiosyncratic DILI was found to account for approximately $11 \%$ of all cases of acute liver failure, and the prevalence of drug-induced cholestasis was reported to be $20 \%$ in an elderly population. ${ }^{13,14}$ Anti-infective drugs, nonsteroidal anti-inflammatory drugs, and herbal and dietary supplements are common causes of DILI in the developed countries of North America and Europe. ${ }^{15}$ American data showed that herbal and dietary supplements accounted for more than $20 \%$ of the causes of DILI. ${ }^{16}$ Specifically, amoxicillin/clavulanate remains the predominant cause of cholestatic DILI. ${ }^{17}$ Furthermore, the same drug can cause different types of liver damage. ${ }^{18}$ Imprudent alcohol consumption may increase the risk of DILI. ${ }^{4}$

\section{Formation of BAs and their toxic potential}

Primary BAs, cholic acid (CA) and chenodeoxycholic acid are synthesized from cholesterol in the liver. ${ }^{19}$ These BAs can be subjected to enzyme-catalyzed conjugation to form taurocholic acid, glycocholic acid, glycochenodeoxycholic (GCDCA) 
and taurochenodeoxycholic acid. ${ }^{20}$ These BAs can also be actively transported out of the liver and into the bile. Bile is a toxic substance, but the toxic effect of bile on hepatocytes and bile duct epithelial cells can be minimized physiologically through various mechanisms, such as high apical membrane cholesterol and sphingomyelin content, bile hydration and alkalization, micellar binding of BAs, mucin formation (in larger ducts and gallbladder), and particularly bile flow, which limits the interaction time of bile with cell membrane domains. ${ }^{21-23}$

Disruption of normal hepatobiliary transport may expose cells to the toxic effects of bile, resulting in hepatocellular and bile duct injury. ${ }^{24}$ GCDCA and its bile salt glycochenodeoxycholate are major constituents of bile during cholestasis. ${ }^{25}$ Several mechanisms have been proposed by which GCDCA executes its toxic effect, including DNA fragmentation, cellular shrinkage and blebbing of the membrane, chromatin margination and condensation, and apoptosis. ${ }^{26}$ Additionally, studies have shown that cellular apoptosis is associated with mitochondrial instability and mitochondrial membrane permeability transition pore formation. ${ }^{25}$

Considering all of these facts about BAs, their formation, bile flow, and toxic effect, it is clear that any disturbance in normal bile flow can have significant consequences on the liver. In the following paragraphs various factors involved in bile transport and flow will be discussed as potential targets of drug hepatotoxic effect.

\section{Hepatic canalicular efflux transport proteins}

Transport of biliary constituents across the canalicular membrane represents the rate limiting step in bile formation and excretion. ${ }^{1}$ This process is regulated by ATP-dependent canalicular transporters, especially the bile salt export pump [known as BSEP and ATP-binding cassette (ABCB11)].

BSEP represents a hepatic transport protein that is a member of the $A B C$ gene superfamily, and represents the major determinant of bile salt-dependent canalicular bile secretion. ${ }^{1,2,27}$ Various drugs involved in cholestatic or mixed cholestatic and hepatocellular liver injury inhibit BSEP-mediated biliary excretion of BAs, consequently leading to an increase in hepatic exposure to cytotoxic effects of BAs in susceptible individuals, ${ }^{1,28}$ as presented in Table 1 . Some of these drugs are bosentan, cyclosporine, rifampin, troglitazone, sulindac, erythromycin, and glibenclamide. ${ }^{1}$ Additionally, some drugs, such as taxol and pravastatin, are transported by BSEP, and therefore may be involved in drug-induced cholestasis. ${ }^{2}$ Most of the BSEP inhibitors directly cis-inhibit BSEP. In contrast, estradiol $17 \beta$-glucuronide and progesterone metabolites represent indirect trans-inhibitors of BSEP. ${ }^{29}$ Prior to trans-inhibition, these drugs are secreted into the bile by another ATP-dependent transporter, the multidrug resistance-associated protein (MRP)-2, and then exert their inhibitory effect from the luminal side of the canalicular membrane. ${ }^{2,30}$ Although BSEP inhibition increases risk for development of liver injury, it is considered that inhibition alone is not enough, and in many cases, the pathological mechanism is more complicated. Cyclosporine can induce cholestatic liver injury through various mechanisms, such as competitive inhibition of ATP transporters, intrahepatic vesicle transport inhibition, targeting of ATP dependent transporters to the apical (canalicular) membrane, and impairment of bile excretion by increasing membrane fluidity without affecting the expression of canalicular transporters. ${ }^{31}$
Other ATP-dependent transporters are MDR1 (ABCB1) and MDR3 (ABCB4), MRP2 (ABCC2), breast cancer resistance protein (ABCG2), cholesterol flippase (ABCG5), and ABCG8. ${ }^{2,32}$

MDR3 represents an ATP-dependent phospholipid flippase that is able to translocate phosphatidylcholine from the inner to the outer leaflet of the canalicular membrane. ${ }^{32}$ Phosphatidylcholine is solubilized by canalicular bile salts to form mixed micelles, consequently protecting the biliary epithelium from exposure to the toxic and detergent effects of BAs which could result in cholangiopathy. ${ }^{1,33}$ Various studies confirmed itraconazole as an MDR3 inhibitor which reduces MDR3-mediated efflux of phosphatidylcholine. ${ }^{34}$ However, BSEP-mediated BA transport was not affected, suggesting that although inhibition of MDR3mediated biliary phospholipid excretion may represent a risk factor for drug-induced cholestasis, BA secretion is not altered. ${ }^{1}$ In vitro studies showed that drugs, such as verapamil and cyclosporine, are transported by MDR3, potentially leading to competitive inhibition of phospholipid flippase activity and cholestatic injury. ${ }^{34}$ Additionally, various genetic variations in BSEP and MDR3 could predispose individuals to drug-induced cholestasis. ${ }^{35}$

MRP2 plays an important role in detoxification and chemoprotection by transporting into bile a wide range of compounds, especially conjugates of lipophilic substances with glutathione (GSH), glucoronate, and sulfate (phase II products of biotransformation). ${ }^{36}$ Additionally, MRP2 is able to cotransport uncharged compounds with GSH, consequently modulating the pharmacokinetics of numerous drugs. ${ }^{36}$ MRP2 regulates bile salt-independent bile flow by excretion of glutathione. ${ }^{37}$ Accordingly, Fouassier et al. ${ }^{38}$ showed that bosentan (competitive antagonist of endothelin-1) stimulates MRP2-dependent bilirubin secretion and bile saltindependent bile flow, whereas phospholipid and cholesterol excretion were markedly inhibited and uncoupled from bile salt excretion. Alpha-naphthylisothiocyanate forms a labile GSH adduct in hepatocytes, which is afterwards transported into alkaline bile and finally dissociates, with a potential to induce cholestatic bile duct injury. ${ }^{2}$ It has been shown that rats with a mutation in MRP2 are unable to pump the adduct into bile and, therefore, are protected from alpha-naphthylisothiocyanate-induced cholestatic injury. ${ }^{39}$

Drug metabolites, such as troglitazone sulfate and troglitazone glucuronide are both eliminated by MRP2 into bile, suggesting that canalicular elimination by MRP2 may represent an important factor in the pathogenesis of troglitazoneinduced cholestatic injury. ${ }^{40}$ Additionally, direct competition of the above-mentioned troglitazone metabolites with conjugated bilirubin at the level of MRP2 could result in conjugated hyperbilirubinemia. ${ }^{40}$ These metabolites are also capable of cis-inhibiting BSEP and, therefore, inducing the cholestasis and hepatotoxicity. ${ }^{41,42}$ A previously mentioned drug, cyclosporine, is proposed to reduce expression of GSH synthesizing enzymes, and the MRP2 system, consequently leading to decreased bile salt-independent bile flow and hepatotoxicity. ${ }^{2}$ Co-administration with rapamycin can exacerbate the cholestatic effect of cyclosporine. ${ }^{43}$

The effects of various drugs on the function of hepatic efflux transport proteins are very diverse. Some affect efflux of bile to the canaliculi, while others involve protection of biliary epithelium. Inhibition of any of these functions predisposes liver tissue to toxic effects of bile. However, there are many compensatory mechanisms which can reverse the 
Kolarić T.O. et al: Mechanisms of cholestatic drug injury

Table 1. List of the most important hepatic transporters, their locations, functions and drugs that act as their inhibitors

\begin{tabular}{|c|c|c|c|}
\hline $\begin{array}{l}\text { Hepatic } \\
\text { transporter }\end{array}$ & $\begin{array}{l}\text { Location in } \\
\text { hepatocytes }\end{array}$ & Function & Inhibitors \\
\hline BSEP & $\begin{array}{l}\text { Canalicular } \\
\text { membrane }\end{array}$ & $\begin{array}{l}\text { ATP-dependent transport of bile salts, } \\
\text { taxol and pravastatin }\end{array}$ & $\begin{array}{l}\text { Bosentan, cyclosporine, rifampin, troglitazone, } \\
\text { sulindac, erythromycin, glibenclamide, } \\
\text { progesterone metabolites, estradiol } \\
17 \beta \text {-glucuronide }\end{array}$ \\
\hline MDR3 & $\begin{array}{l}\text { Canalicular } \\
\text { membrane }\end{array}$ & $\begin{array}{l}\text { ATP-dependent excretion of } \\
\text { phosphatidylcholine }\end{array}$ & $\begin{array}{l}\text { Itraconazole, chlorpromazine, imipramine, } \\
\text { haloperidol, ketoconazole, clotrimazole, } \\
\text { troglitazone }\end{array}$ \\
\hline MRP2 & $\begin{array}{l}\text { Canalicular } \\
\text { membrane }\end{array}$ & $\begin{array}{l}\text { ATP-dependent efflux of numerous drugs, } \\
\text { organic anions and bile acids, bile salt- } \\
\text { independent bile flow by GSH transport }\end{array}$ & $\begin{array}{l}\text { Cyclosporine, efavirenz, benzbromarone, } \\
\text { probenecid }\end{array}$ \\
\hline MDR1 & $\begin{array}{l}\text { Canalicular } \\
\text { membrane }\end{array}$ & $\begin{array}{l}\text { ATP-dependent efflux of numerous drugs, } \\
\text { organic cations and bile acids }\end{array}$ & $\begin{array}{l}\text { Cyclosporine, carvedilol, clarithromycin, } \\
\text { amiodarone, itraconazole, lapatinib, verapamil }\end{array}$ \\
\hline BCRP & $\begin{array}{l}\text { Canalicular } \\
\text { membrane }\end{array}$ & ATP-dependent efflux of anticancer drugs & $\begin{array}{l}\text { Gefitinib, mesylate, } 17 ß \text {-estradiol, ritonavir, } \\
\text { omeprazole, cyclosporine }\end{array}$ \\
\hline MRP3 & $\begin{array}{l}\text { Basolateral } \\
\text { membrane }\end{array}$ & $\begin{array}{l}\text { ATP-dependent efflux of drug glucuronide } \\
\text { conjugates }\end{array}$ & $\begin{array}{l}\text { Tenofovir, indomethacin, furosemide, } \\
\text { probenecid, non-nucleoside reverse } \\
\text { transcriptase inhibitors (delavirdine, efavirenz, } \\
\text { and nevirapine), and nucleoside reverse } \\
\text { transcriptase inhibitors (emtricitabine and } \\
\text { lamivudine) }\end{array}$ \\
\hline MRP4 & $\begin{array}{l}\text { Basolateral } \\
\text { membrane }\end{array}$ & $\begin{array}{l}\text { ATP-dependent efflux of sulfated drugs } \\
\text { and bile acids }\end{array}$ & $\begin{array}{l}\text { Troglitazone sulfate, NSAIDs, } \\
\text { phosphodiesterase inhibitors, verapamil, } \\
\text { losartan, silymarin, probenecid }\end{array}$ \\
\hline NTCP & $\begin{array}{l}\text { Basolateral } \\
\text { membrane }\end{array}$ & $\begin{array}{l}\text { Uptake of bile-salts from portal blood, } \\
\text { transport of rosuvastatin }\end{array}$ & $\begin{array}{l}\text { Cyclosporine, bosentan, troglitazone, } \\
\text { propranolol, furosemide, ketoconazole, } \\
\text { renin inhibitors and a somatostatin } \\
\text { analogue, rifamycin }\end{array}$ \\
\hline OATPS & $\begin{array}{l}\text { Basolateral } \\
\text { membrane }\end{array}$ & $\begin{array}{l}\text { Sodium-independent uptake of bile salts, } \\
\text { organic anions, and numerous drugs }\end{array}$ & $\begin{array}{l}\text { Itraconazole, nefazodone, nifedipine, } \\
\text { reserpine, diazepam, sulfasalazine }\end{array}$ \\
\hline
\end{tabular}

Data from Yang et al., ${ }^{1}$ solvobiotech.com, ${ }^{44}$ Kim et al. ${ }^{48}$ and Kalgren et al. ${ }^{51}$

Abbreviations: BCRP, Breast cancer resistance protein; BSEP, bile salt export pump; MDR, multidrug resistance; MRP, multidrug resistance-associated protein; NSAID, nonsteroidal anti-inflammatory drugs; NTCP, sodium-taurocholate cotransporting polypeptide; OATPs, organic anion transporting polypeptides.

hepatotoxic effect of drugs. One of the major mechanisms involves canalicular efflux transporters.

\section{Hepatic basolateral efflux transport proteins}

Inhibition of each one of the above-mentioned hepatic canalicular efflux transporters represents a risk factor for druginduced cholestasis. Nevertheless, as explained before, not all drugs that inhibit these transporters cause cholestasis because there are several compensatory mechanisms of bile transport present in the hepatocytes. ${ }^{1}$ In contrast to BSEP, MRP2, breast cancer resistance protein, and MDR1, MRP3 and MRP4 transporters are expressed on the basolateral (vascular) side of the polarized cells, which means that in the liver they efflux their substrates into the blood rather than into the bile. Under the normal conditions, these transporters play a minor role in BA efflux, whereas under cholestatic conditions their expression is induced in order to compensate for impaired biliary excretion. ${ }^{44-46}$ Compensatory basolateral efflux prevents hepatic BA accumulation, leading to increased renal elimination of BAs. ${ }^{1}$ Therefore, impaired function of MRP3 and MRP4 by various drugs may result in accumulation of toxic BAs in hepatocytes. ${ }^{1}$ Substrates of MRP3 transporters include endogenous compounds (estradiol-17 $\beta$-glucuronide, leukotriene C4, and monovalent bile salts such as cholate and glycocholate), chemotherapeutic agents, acetaminophen-glucuronide, morphine-3-glucuronide, and fexofenadine. 47,48

In contrast to the previously mentioned MRP1 and MRP2 transporters, MRP3 expresses a higher affinity for glucuronide conjugates compared to GSH conjugates, and unlike MRP1 and MRP2 MRP3 does not require GSH to transport substrates. $^{49}$ Several drugs are inhibitors of MRP3, including tenofovir, indomethacin, furosemide, probenecid, nonnucleoside reverse transcriptase inhibitors (delavirdine, efavirenz, and nevirapine), and nucleoside reverse transcriptase inhibitors (emtricitabine and lamivudine). ${ }^{50}$ Troglitazone sulfate is capable of inhibiting both canalicular BSEP and basolateral MRP4 efflux of BAs at the same time, predisposing hepatocytes to toxicity. ${ }^{1}$ Basolateral efflux proteins are capable of diminishing drug hepatotoxic effects through various mechanisms, all of which result in reduction of BA accumulation in hepatocytes. Therefore, drugs which decrease activity of these transporters can expose liver cells to BA toxic effects, especially in combination with inhibition of canalicular efflux proteins. 
Kolarić T.O. et al: Mechanisms of cholestatic drug injury

\section{Hepatic uptake transport proteins}

The uptake transport proteins sodium-taurocholate cotransporting polypeptide (NTCP) and organic anion transporting polypeptides (OATPs) are involved in taking up BAs from the portal vein into hepatocytes ${ }^{1,51}$ (Fig. 1). Basolateral uptake transporters play major roles in controlling the response to hepatic and systemic exposure to drugs and toxins. The hepatic accumulation of BAs is regulated by both uptake and efflux (basolateral and canalicular) processes. Thus, inhibition of hepatic BA uptake could diminish intracellular bile salt concentrations in hepatocytes and consequently lower the cytotoxic action of bile salts. ${ }^{1,51}$

NTCP, an electrogenic transporter, is responsible for sodium-dependent bile salt uptake, and it transports two sodium ions together with one bile salt molecule. ${ }^{52,53}$ Because it is an energy-dependent transporter, NTCP is capable of taking up bile salt from the portal blood into hepatocytes against a concentration gradient. ${ }^{51}$ It has greater affinity of transporting trihydroxy and conjugated as opposed to dihydroxy and unconjugated BAs. However, NTCP is also able to mediate the transport of drugs and toxins. ${ }^{1,51}$ Regulation of NTCP is associated with changes in bile salt load to hepatocytes; the main goals are to prevent entry of cytotoxic bile salts during liver disease and to maintain BA homeostasis inside hepatocytes. ${ }^{51}$

NTCP is a target of inhibition by numerous drugs, such as cyclosporine, bosentan, troglitazone, propranolol, furosemide, ketoconazole, renin inhibitors and a somatostatin analogue, as well as rifamycin. ${ }^{54}$ Additionally, differential effects of drugs on individual BAs' accumulation should be considered when predicting hepatotoxicity in humans. ${ }^{1}$ Although, inhibition of NTCP should lead to an increase of serum bile salt levels, the effects may be inconsistent because the liver also expresses sodium-independent bile salt transporters, such as the OATPs, which can partly compensate for the inhibition of NTCP. ${ }^{51}$ Nevertheless, these drugs often have the capability of inhibiting OATPs in addition to
NTCP, as demonstrated for rifampicin and rifamycin and for cyclosporine. ${ }^{55,56}$

Many drugs are substrates of the OATPs, such as statins, bosentan, and angiotensin-converting enzyme inhibitors. Drugs that may inhibit OATP transporters are itraconazole, nefazodone, nifedipine, reserpine, diazepam, sulfasalazine, etc. $^{57}$ Additionally, there are some individual differences between different drugs in inhibiting a specific OATP transporter, considering that different types of OATP transporter are present (OATP1B1, OATP1B3, and OATP2B1). ${ }^{57}$ Hepatic uptake is another mechanism for maintaining BA homeostasis in liver cells. Therefore, any drug that disturbs this function, particularly when liver injury is already present, can result in deterioration of liver function.

\section{Metabolic defects}

To date, nine congenital errors of BA synthesis have been reported. Congenital errors in BA metabolism have been identified by analysis of abnormal BA metabolites and mutations or enzyme deficiencies that can be caused by a primary defect in the enzymes involved in the BA biosynthetic pathways. Congenital errors of BA synthesis can produce abnormal BA metabolites, with modified steroid side chains or steroid nucleus structure. Such metabolites can be toxic and capable of causing cholestatic liver disease and progressive neurological disease. ${ }^{58,59}$

BAs are crucial physiological agents, signaling molecules and metabolic regulators that activate nuclear receptors and $G$ protein-coupled receptors, such as farnesoid $X$, pregnane $X$, constitutive androstane receptors, and vitamin $D$ receptor signaling to control hepatic lipid, glucose, and energy homeostasis and maintain metabolic homeostasis. ${ }^{60,61}$ Disturbances in BA metabolism can cause cholestatic liver diseases, dyslipidemia, fatty liver diseases, cardiovascular diseases, and diabetes. However, acid-activated nuclear and $G$ proteincoupled receptor signaling protects against inflammation in the liver and intestines, and macrophages. ${ }^{59}$ AMP-activated protein kinase is a critical player in the pathogenesis of

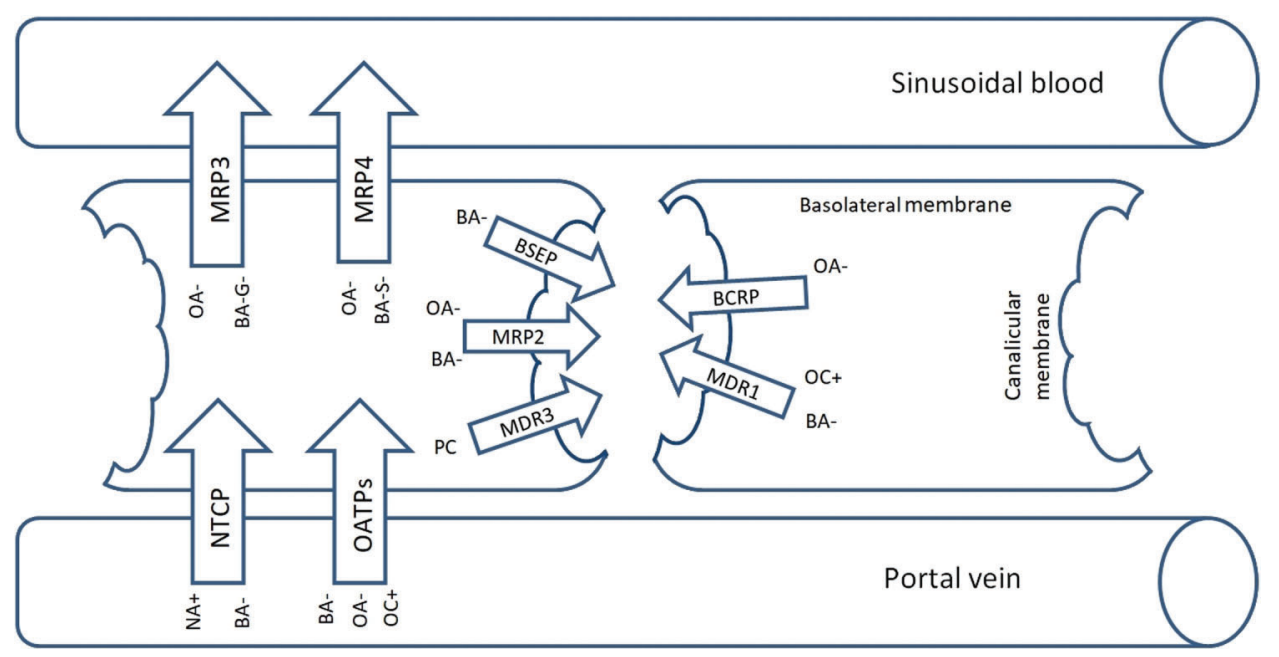

Fig. 1. Localization of the most important hepatic transporters in hepatocytes. Abbreviations: MRP3, multidrug resistance-associated protein 3; MRP4, multidrug resistance-associated protein 4; NTCP, sodium-taurocholate cotransporter; OATPs, organic anion transporting polypeptides; BSEP, bile salt export pump; MRP2, multidrug resistance-associated protein 2; MDR3, multidrug resistance protein-3; BCRP, breast cancer resistance protein; MDR1, multidrug resistance protein 1; OA, organic anion; BA-G, bile acid glucuronide; BA-S, bile acid sulfate; NA, sodium; BA, bile acid; OC, organic cation; PC, phosphatidylcholine. 
cholestatic liver injury that induces suppression of the nuclear receptor, disturbs BA homeostasis, and facilitates inflammation at the late stages. Potentially, AMP-activated protein kinase is therapeutic target for the treatment of cholestatic liver injury. ${ }^{62}$

\section{Mitochondrial damage}

Mitochondrial biogenesis is a complex process, wherein the peroxisome proliferator-activated receptor $\mathrm{G}$ coactivator $1 \mathrm{a}$ is a key regulator. ${ }^{63,64}$ Mitochondria serve as the main energy producers in hepatocytes ${ }^{65}$ through their role in fatty acid oxidation, pyruvate oxidation, and the oxidative phosphorylation system, as well as the electron transport chain. Because of its importance in energetics, it is not surprising that mitochondria are also at the center of signaling pathways that mediate hepatocyte damage. ${ }^{66,67}$ Genetic factors, hormones, post-infectious factors and drugs can all result in harmful effects on mitochondrial function. ${ }^{68}$

DILI affecting the mitochondrial function is common. When mitochondrial injury results in canalicular membrane damage or transporter dysfunction, cholestatic liver injury can result. Hepatotoxic drugs cause mitochondrial dysfunction through different mechanisms, like membrane permeabilization, oxidative phosphorylation system impairment, and mitochondrial DNA depletion; subsequently, some drugs directly inhibit mitochondrial respiration and the mitochondrial $\beta$-oxidation of fatty acids. The conversion of a nontoxic drug into a chemically reactive metabolite is the most frequent mechanism of DILI. ${ }^{66,68,69}$ Some marketed drugs have received Black Box warnings from drug agencies due to mitochondrial dysfunction and related hepatotoxicity; as well, some examples of DILI resulting from mitochondrial dysfunction have prevented the marketing of some compounds, led to the repeal of diethylaminoethoxyhexestrol, nefazodone, troglitazone and trovafloxacin, and led to restricted use of perhexiline, as well as the early therapeutic misadventures with tetracyclines and valproic acid.

BAs are the major organic solutes in bile. Retention of hydrophobic BAs during cholestasis plays an important role in liver injury through apoptosis or necrosis of hepatocytes. Hepatocyte injury caused by the retention of hydrophobic BAs and mitochondrial dysfunction has been associated with liver cholestasis. Toxic bile salt accumulation can lead to chronic injury with mitochondrial damage, increase in reactive oxygen species, and apoptosis which can result in liver dysfunction. ${ }^{70,71}$ Induction of the mitochondrial permeability transition (MPT) is known to play a key role in cell death, and mitochondrial permeability transition induction is involved in BA cytotoxicity. ${ }^{72,73}$ Mitochondrial dysfunction can occur in death receptor-mediated apoptosis, and also by DCAtriggered apoptosis in reduced mitochondrial membrane potential and modifications in Bax subcellular distribution. ${ }^{74}$ Pretreatment with cyclosporin A, a specific and potent inhibitor of the mitochondrial permeability transition, protects cells from cell death, prevents mitochondrial swelling, and diminishes the efflux of cytochrome $c$ induced by DCA, a hydrophobic BA. ${ }^{74,75}$ High concentrations of BAs cause disruption of plasma membrane integrity. In chronic cholestasis, mitochondrial calcium homeostasis can be severely damaged. In cholestatic liver diseases, ursodeoxycholic acid is used as a therapeutic agent because of its ability to modulate hydrophobic BA-induced damage in hepatocytes. ${ }^{71,76}$ However, this does not address the underlying mechanism of cholestatic disease. Cholestasis and its related complications still remain therapeutic challenges, and new effective agents are much needed. At present, aside from liver transplantation, there is no method to reverse injury due to hepatic mitochondria or to replace them. Recent studies, however, have suggested that targeted mitochondrial transplantation in hepatocytes is possible. $^{77}$

\section{Conclusions}

Drugs represent an important cause of severe liver injury and acute fulminant liver failure. Despite the progress that has been made in our understanding of the mechanisms involved in drug-induced cholestatic liver injury, adequate therapeutic measures are lacking. The fact that drugs can act through many different mechanisms to cause cholestasis makes prompt diagnosis and effective therapy a challenge.

\section{Conflict of interest}

The authors have no conflict of interests related to this publication.

\section{Author contributions}

Conceived the article outline (GYW), critical revision, funding, administration, and technical support (GYW, MS), writing of the manuscript (TOK, VN), literature searches and text update (RS).

\section{References}

[1] Yang K, Köck K, Sedykh A, Tropsha A, Brouwer KL. An updated review on drug-induced cholestasis: mechanisms and investigation of physicochemical properties and pharmacokinetic parameters. J Pharm Sci 2013;102:30373057. doi: 10.1002/jps.23584.

[2] Padda MS, Sanchez M, Akhtar AJ, Boyer JL. Drug-induced cholestasis. Hepatology 2011;53:1377-1387. doi: 10.1002/hep.24229.

[3] Rabinowich L, Shibolet O. Drug induced steatohepatitis: An uncommon culprit of a common disease. Biomed Res Int 2015;2015:168905. doi: 10. $1155 / 2015 / 168905$.

[4] Chalasani NP, Hayashi PH, Bonkovsky HL, Navarro VJ, Lee WM, Fontana RJ. ACG Clinical Guideline: the diagnosis and management of idiosyncratic druginduced liver injury. Am J Gastroenterol 2014;109:950-966. doi: 10. 1038/ajg.2014.131.

[5] Temple R. Hy's law: predicting serious hepatotoxicity. Pharmacoepidemiol Drug Saf 2006;15:241-243. doi: 10.1002/pds.1211.

[6] Fontana RJ. Acute liver failure including acetaminophen overdose. Med Clin North Am 2008;92:761-794. doi: 10.1016/j.mcna.2008.03.005.

[7] Lee WM. Drug-induced hepatotoxicity. N Engl ] Med 2003;349:474-485. doi: 10.1056/NEJMra021844.

[8] Bhamidimarri KR, Schiff E. Drug-induced cholestasis. Clin Liver Dis 2013;17: 519-531. doi: 10.1016/j.cld.2013.07.015.

[9] Sgro C, Clinard F, Ouazir K, Chanay H, Allard C, Guilleminet C, et al. Incidence of drug-induced hepatic injuries: a French population-based study. Hepatology 2002;36:451-455. doi: 10.1053/jhep.2002.34857.

[10] Björnsson ES, Bergmann OM, Björnsson HK, Kvaran RB, Olafsson S. Incidence, presentation, and outcomes in patients with drug-induced liver injury in the general population of Iceland. Gastroenterology 2013;144: 1419-1425.e3. doi: 10.1053/j.gastro.2013.02.006.

[11] Larrey D. Epidemiology and individual susceptibility to adverse drug reactions affecting the liver. Semin Liver Dis 2002;22:145-155. doi: 10.1055/s2002-30105.

[12] Ettel M, Gonzalez GA, Gera S, Eze O, Sigal S, Park JS, et al. Frequency and pathological characteristics of drug-induced liver injury in a tertiary medical center. Hum Pathol 2017;68:92-98. doi: 10.1016/j.humpath.2017.08.029.

[13] Reuben A, Koch DG, Lee WM. Drug-induced acute liver failure: results of a U.S. multicenter, prospective study. Hepatology 2010;52:2065-2076. doi: 10.1002/hep.23937.

[14] Lewis JH. Drug-induced liver disease. Med Clin North Am 2000;84:12751311. doi: 10.1016/S0025-7125(05)70287-X. 
[15] Russo MW, Galanko JA, Shrestha R, Fried MW, Watkins P. Liver transplantation for acute liver failure from drug induced liver injury in the United States. Liver Transpl 2004;10:1018-1023. doi: 10.1002/It.20204.

[16] Li L, Jiang W, Wang J. Clinical analysis of 275 cases of acute drug-induced liver disease. Front Med China 2007;1:58-61. doi: 10.1007/s11684-0070012-8.

[17] Sundaram V, Björnsson ES. Drug-induced cholestasis. Hepatol Commun 2017; 1:726-735. doi: 10.1002/hep4.1088.

[18] Yu YC, Mao YM, Chen CW, Chen JJ, Chen J, Cong WM, et al. CSH guidelines for the diagnosis and treatment of drug-induced liver injury. Hepatol Int 2017; 11:221-241. doi: 10.1007/s12072-017-9793-2.

[19] Gonzalez FJ. Nuclear receptor control of enterohepatic circulation. Compr Physiol 2012;2:2811-2828. doi: 10.1002/cphy.c120007.

[20] Rodrigues AD, Lai Y, Cvijic ME, Elkin LL, Zvyaga T, Soars MG. Drug-induced perturbations of the bile acid pool, cholestasis, and hepatotoxicity: mechanistic considerations beyond the direct inhibition of the bile salt export pump. Drug Metab Dispos 2014;42:566-574. doi: 10.1124/dmd.113.054205.

[21] Hofmann AF. Bile acids as drugs: principles, mechanisms of action and formulations. Ital J Gastroenterol 1995;27:106-113.

[22] Hofmann AF. The continuing importance of bile acids in liver and intestinal disease. Arch Intern Med 1999;159:2647-2658. doi: 10.1001/archinte.159. 22.2647.

[23] Trauner M, Fickert P, Halilbasic E, Moustafa T. Lessons from the toxic bile concept for the pathogenesis and treatment of cholestatic liver diseases. Wien Med Wochenschr 2008;158:542-548. doi: 10.1007/s10354-0080592-1.

[24] Trauner M, Fickert P, Wagner M. MDR3 (ABCB4) defects: a paradigm for the genetics of adult cholestatic syndromes. Semin Liver Dis 2007;27:77-98. doi: $10.1055 / \mathrm{s}-2006-960172$.

[25] Woolbright BL, Jaeschke H. Novel insight into mechanisms of cholestatic liver injury. World J Gastroenterol 2012;18:4985-4993. doi: 10.3748/wjg.v18. i36.4985.

[26] Patel T, Bronk SF, Gores GJ. Increases of intracellular magnesium promote glycodeoxycholate-induced apoptosis in rat hepatocytes. J Clin Invest 1994; 94:2183-2192. doi: 10.1172/JCI117579.

[27] Stieger B. Role of the bile salt export pump, BSEP, in acquired forms of cholestasis. Drug Metab Rev 2010;42:437-445. doi: 10.3109/03602530903492004.

[28] Lee JK, Paine MF, Brouwer KL. Sulindac and its metabolites inhibit multiple transport proteins in rat and human hepatocytes. J Pharmacol Exp Ther 2010;334:410-418. doi: 10.1124/jpet.110.165852.

[29] Stieger B, Fattinger K, Madon J, Kullak-Ublick GA, Meier PJ. Drug- and estrogen-induced cholestasis through inhibition of the hepatocellular bile salt export pump (Bsep) of rat liver. Gastroenterology 2000;118:422-430. doi: 10.1016/s0016-5085(00)70224-1.

[30] Dietschy JM. Mechanisms for the intestinal absorption of bile acids. J Lipid Res 1968;9:297-309.

[31] Yasumiba S, Tazuma S, Ochi H, Chayama K, Kajiyama G. Cyclosporin A reduces canalicular membrane fluidity and regulates transporter function in rats. Biochem J 2001;354:591-596. doi: 10.1042/bj3540591.

[32] de Lima Toccafondo Vieira M, Tagliati CA. Hepatobiliary transporters in druginduced cholestasis: a perspective on the current identifying tools. Expert Opin Drug Metab Toxicol 2014;10:581-597. doi: 10.1517/17425255.2014. 884069.

[33] Mauad TH, van Nieuwkerk CM, Dingemans KP, Smit J], Schinkel AH, Notenboom RG, et al. Mice with homozygous disruption of the mdr2 P-glycoprotein gene. A novel animal model for studies of nonsuppurative inflammatory cholangitis and hepatocarcinogenesis. Am J Pathol 1994; 145:1237-1245.

[34] Yoshikado T, Takada T, Yamamoto T, Yamaji H, Ito K, Santa T, et al. Itraconazole-induced cholestasis: involvement of the inhibition of bile canalicular phospholipid translocator MDR3/ABCB4. Mol Pharmacol 2011;79:241-250. doi: 10.1124/mol.110.067256.

[35] Meier Y, Zodan T, Lang C, Zimmermann R, Kullak-Ublick GA, Meier PJ, et al. Increased susceptibility for intrahepatic cholestasis of pregnancy and contraceptive-induced cholestasis in carriers of the $1331 \mathrm{~T}>\mathrm{C}$ polymorphism in the bile salt export pump. World J Gastroenterol 2008;14:38-45. doi: 10. 3748/wjg.14.38.

[36] Jedlitschky G, Hoffmann U, Kroemer HK. Structure and function of the MRP2 (ABCC2) protein and its role in drug disposition. Expert Opin Drug Metab Toxicol 2006;2:351-366. doi: 10.1517/17425255.2.3.351.

[37] Trauner M, Meier PJ, Boyer JL. Molecular pathogenesis of cholestasis. N Engl J Med 1998;339:1217-1227. doi: 10.1056/NEJM199810223391707.

[38] Fouassier L, Kinnman N, Lefèvre G, Lasnier E, Rey C, Poupon R, et al. Contribution of mrp2 in alterations of canalicular bile formation by the endothelin antagonist bosentan. J Hepatol 2002;37:184-191. doi: 10.1016/S01688278(02)00107-1.

[39] Dietrich CG, Ottenhoff R, de Waart DR, Oude Elferink RP. Role of MRP2 and GSH in intrahepatic cycling of toxins. Toxicology 2001;167:73-81. doi: 10. 1016/S0300-483X(01)00459-0.
[40] Kostrubsky VE, Vore M, Kindt E, Burliegh J, Rogers K, Peter G, et al. The effect of troglitazone biliary excretion on metabolite distribution and cholestasis in transporter-deficient rats. Drug Metab Dispos 2001;29:1561-1566.

[41] Funk C, Pantze M, Jehle L, Ponelle C, Scheuermann G, Lazendic M, et al. Troglitazone-induced intrahepatic cholestasis by an interference with the hepatobiliary export of bile acids in male and female rats. Correlation with the gender difference in troglitazone sulfate formation and the inhibition of the canalicular bile salt export pump (Bsep) by troglitazone and troglitazone sulfate. Toxicology 2001;167:83-98. doi: 10.1016/S0300-483X(01) 00460-7.

[42] Funk C, Ponelle C, Scheuermann G, Pantze M. Cholestatic potential of troglitazone as a possible factor contributing to troglitazone-induced hepatotoxicity: in vivo and in vitro interaction at the canalicular bile salt export pump (Bsep) in the rat. Mol Pharmacol 2001;59:627-635. doi: 10.1124/mol.59.3. 627.

[43] Bramow S, Ott P, Thomsen Nielsen F, Bangert K, Tygstrup N, Dalhoff K. Cholestasis and regulation of genes related to drug metabolism and biliary transport in rat liver following treatment with cyclosporine $A$ and sirolimus (Rapamycin). Pharmacol Toxicol 2001;89:133-139. doi: 10.1034/j.16000773.2001.d01-147.x.

[44] Denk GU, Soroka CJ, Takeyama Y, Chen WS, Schuetz JD, Boyer JL. Multidrug resistance-associated protein 4 is up-regulated in liver but down-regulated in kidney in obstructive cholestasis in the rat. J Hepatol 2004;40:585-591. doi: 10.1016/j.jhep.2003.12.001.

[45] Soroka C], Lee JM, Azzaroli F, Boyer JL. Cellular localization and up-regulation of multidrug resistance-associated protein 3 in hepatocytes and cholangiocytes during obstructive cholestasis in rat liver. Hepatology 2001;33:783791. doi: 10.1053/jhep.2001.23501.

[46] Donner MG, Keppler D. Up-regulation of basolateral multidrug resistance protein 3 (Mrp3) in cholestatic rat liver. Hepatology 2001;34:351-359. doi: 10.1053/jhep.2001.26213.

[47] Zhou SF, Wang LL, Di YM, Xue CC, Duan W, Li CG, et al. Substrates and inhibitors of human multidrug resistance associated proteins and the implications in drug development. Curr Med Chem 2008;15:1981-2039. doi: 10. 2174/092986708785132870.

[48] Patel M, Taskar KS, Zamek-Gliszczynski MJ. Importance of hepatic transporters in clinical disposition of drugs and their metabolites. J Clin Pharmacol 2016;56:S23-S39. doi: 10.1002/jcph.671.

[49] Zelcer N, Saeki T, Reid G, Beijnen JH, Borst P. Characterization of drug transport by the human multidrug resistance protein 3 (ABCC3). J Biol Chem 2001;276:46400-46407. doi: 10.1074/jbc.M107041200.

[50] MRP3 (multidrug resistance-associated protein 3). Availabler from: https: //www.solvobiotech.com/transporters/mrp3.

[51] Stieger B. The role of the sodium-taurocholate cotransporting polypeptide (NTCP) and of the bile salt export pump (BSEP) in physiology and pathophysiology of bile formation. Handb Exp Pharmacol 2011;205-259. doi: 10.1007/978-3-642-14541-4_5.

[52] Hagenbuch B, Meier PJ. Sinusoidal (basolateral) bile salt uptake systems of hepatocytes. Semin Liver Dis 1996;16:129-136. doi: 10.1055/s-20071007226.

[53] Weinman SA. Electrogenicity of $\mathrm{Na}(+)$-coupled bile acid transporters. Yale J Biol Med 1997;70:331-340.

[54] Kim RB, Leake B, Cvetkovic M, Roden MM, Nadeau J, Walubo A, et al. Modulation by drugs of human hepatic sodium-dependent bile acid transporter (sodium taurocholate cotransporting polypeptide) activity. J Pharmacol Exp Ther 1999;291:1204-1209.

[55] Fattinger K, Cattori V, Hagenbuch B, Meier PJ, Stieger B. Rifamycin SV and rifampicin exhibit differential inhibition of the hepatic rat organic anion transporting polypeptides, Oatp1 and Oatp2. Hepatology 2000;32:82-86. doi: 10.1053/jhep.2000.8539.

[56] Treiber A, Schneiter R, Häusler S, Stieger B. Bosentan is a substrate of human OATP1B1 and OATP1B3: inhibition of hepatic uptake as the common mechanism of its interactions with cyclosporin A, rifampicin, and sildenafil. Drug Metab Dispos 2007;35:1400-1407. doi: 10.1124/dmd.106. 013615.

[57] Karlgren M, Vildhede A, Norinder U, Wisniewski JR, Kimoto E, Lai Y, et al. Classification of inhibitors of hepatic organic anion transporting polypeptides (OATPs): influence of protein expression on drug-drug interactions. J Med Chem 2012;55:4740-4763. doi: 10.1021/jm300212s.

[58] Setchell KD, Street JM. Inborn errors of bile acid synthesis. Semin Liver Dis 1987; 7:85-99. doi: 10.1055/s-2008-1040568.

[59] Clayton PT. Disorders of bile acid synthesis. ] Inherit Metab Dis 2011;34: 593-604. doi: 10.1007/s10545-010-9259-3.

[60] Bjornsson ES, Jonasson JG. Drug-induced cholestasis. Clin Liver Dis 2013; 17:191-209. doi: 10.1016/j.cld.2012.11.002.

[61] Li T, Chiang JY. Bile acid signaling in metabolic disease and drug therapy. Pharmacol Rev 2014;66:948-983. doi: 10.1124/pr.113.008201.

[62] Li X, Liu R, Zhang L, Jiang Z. The emerging role of AMP-activated protein kinase in cholestatic liver diseases. Pharmacol Res 2017;125:105-113. doi: 10.1016/j.phrs.2017.09.002. 
[63] Mitchell P. The Ninth Sir Hans Krebs Lecture. Compartmentation and communication in living systems. Ligand conduction: a general catalytic principle in chemical, osmotic and chemiosmotic reaction systems. Eur J Biochem 1979;95:1-20. doi: 10.1111/j.1432-1033.1979.tb12934.x.

[64] Wallace DC. A mitochondrial paradigm of metabolic and degenerative diseases, aging, and cancer: a dawn for evolutionary medicine. Annu Rev Genet 2005;39:359-407. doi: 10.1146/annurev.genet.39.110304. 095751.

[65] Grattagliano I, Russmann S, Diogo C, Bonfrate L, Oliveira PJ, Wang DQ, et al. Mitochondria in chronic liver disease. Curr Drug Targets 2011;12:879-893. doi: 10.2174/138945011795528877.

[66] Pessayre D, Fromenty $B$, Berson A, Robin MA, Lettéron P, Moreau R, et al. Central role of mitochondria in drug-induced liver injury. Drug Metab Rev 2012;44:34-87. doi: 10.3109/03602532.2011.604086.

[67] Xu F, Liu Y, Zhao H, Yu K, Song M, Zhu Y, et al. Aluminum chloride caused liver dysfunction and mitochondrial energy metabolism disorder in rat. J Inorg Biochem 2017;174:55-62. doi: 10.1016/j.jinorgbio.2017. 04.016.

[68] Fromenty B, Pessayre D. Inhibition of mitochondrial beta-oxidation as a mechanism of hepatotoxicity. Pharmacol Ther 1995;67:101-154. doi: 10 . 1016/0163-7258(95)00012-6.

[69] Pessayre D, Mansouri A, Berson A, Fromenty B. Mitochondrial involvement in drug-induced liver injury. Handb Exp Pharmacol 2010;311-365. doi: 10. 1007/978-3-642-00663-0_11.
[70] de Andrade DC, de Carvalho SN, Pinheiro D, Thole AA, Moura AS, de Carvalho $\mathrm{L}$, et al. Bone marrow mononuclear cell transplantation improves mitochondrial bioenergetics in the liver of cholestatic rats. Exp Cell Res 2015;336: 15-22. doi: 10.1016/j.yexcr.2015.05.002.

[71] Perez MJ, Briz O. Bile-acid-induced cell injury and protection. World J Gastroenterol 2009;15:1677-1689. doi: 10.3748/wjg.15.1677.

[72] Rolo AP, Oliveira PJ, Moreno AJ, Palmeira CM. Bile acids affect liver mitochondrial bioenergetics: possible relevance for cholestasis therapy. Toxicol Sci 2000;57:177-185. doi: 10.1093/toxsci/57.1.177.

[73] Yerushalmi B, Dahl R, Devereaux MW, Gumpricht E, Sokol RJ. Bile acidinduced rat hepatocyte apoptosis is inhibited by antioxidants and blockers of the mitochondrial permeability transition. Hepatology 2001;33:616-626. doi: $10.1053 /$ jhep.2001.22702.

[74] Rodrigues CM, Ma X, Linehan-Stieers C, Fan G, Kren BT, Steer CJ. Ursodeoxycholic acid prevents cytochrome $c$ release in apoptosis by inhibiting mitochondrial membrane depolarization and channel formation. Cell Death Differ 1999;6:842-854. doi: 10.1038/sj.cdd.4400560.

[75] Broekemeier KM, Dempsey ME, Pfeiffer DR. Cyclosporin A is a potent inhibitor of the inner membrane permeability transition in liver mitochondria. J Biol Chem 1989;264:7826-7830.

[76] Palmeira CM, Rolo AP. Mitochondrially-mediated toxicity of bile acids. Toxicology 2004;203:1-15. doi: 10.1016/j.tox.2004.06.001

[77] Gupta N, Wu CH, Wu GY. Targeted transplantation of mitochondria to hepatocytes. Hepat Med 2016;8:115-134. doi: 10.2147/HMER.S116852. 